\title{
Loss of heterophylly in aquatic plants: not ABA-mediated stress but exogenous ABA treatment induces stomatal leaves in Potamogeton perfoliatus
}

\author{
Satoko Iida ${ }^{1} \cdot$ Miyuki Ikeda $^{1} \cdot$ Momoe Amano $^{1} \cdot$ Hidetoshi Sakayama $^{1} \cdot$ \\ Yasuro Kadono $^{1} \cdot$ Keiko Kosuge $^{1}$
}

Received: 28 August 2014 / Accepted: 13 May 2016 / Published online: 21 June 2016

(C) The Botanical Society of Japan and Springer Japan 2016

\begin{abstract}
Heterophyllous aquatic plants produce aerial (i.e., floating and terrestrial) and submerged leaves-the latter lack stomata-while homophyllous plants contain only submerged leaves, and cannot survive on land. To identify whether differences in morphogenetic potential and/or physiological stress responses are responsible for variation in phenotypic plasticity between two plants types, responses to abscisic acid (ABA) and salinity stress were compared between the closely related, but ecologically diverse pondweeds, Potamogeton wrightii (heterophyllous) and P. perfoliatus (homophyllous). The ABA-treated $(1$ or $10 \mu \mathrm{M}) P$. wrightii plants exhibited heterophylly and produced leaves with stomata. The obligate submerged $P$. perfoliatus plants were able to produce stomata on their leaves, but there were no changes to leaf shape, and stomatal production occurred only at a high ABA concentration $(10 \mu \mathrm{M})$. Under salinity stress conditions, only $P$. wrightii leaves formed stomata. Additionally, the expression of stress-responsive NCED genes, which encode a key enzyme in ABA biosynthesis, was consistently up-regulated in $P$. wrightii, but only temporarily in P. perfoliatus. The observed species-specific gene expression patterns may be responsible for the induction or suppression of stomatal production during exposure to salinity stress. These results suggest that the two Potamogeton species have an innate morphogenetic ability to form stomata, but the
\end{abstract}

Electronic supplementary material The online version of this article (doi:10.1007/s10265-016-0844-x) contains supplementary material, which is available to authorized users.

Keiko Kosuge

kosuge@kobe-u.ac.jp

1 Graduate School of Science, Kobe University, 1-1 Rokkodai, Nada, Kobe 657-8501, Japan actual production of stomata depends on ABA-mediated stress responses specific to each species and habitat.

Keywords Abscisic acid (ABA) - Adaptive phenotypic plasticity $\cdot$ Heterophylly $\cdot 9$-cis-epoxycarotenoid dioxygenase $\cdot$ Pondweed $\cdot$ Salinity stress

\section{Introduction}

Many organisms have evolved sophisticated stress response mechanisms, and have acquired the ability to alter their phenotypes to adapt to environmental changes. Bradshaw (1965) suggested that plants should be more plastic, tolerate a broader range of environmental conditions, and experience more persistent natural selection than animals. To survive exposure to various stresses, some plants adopt physiological plasticity, such as acclimation, while others exhibit morphological plasticity. The responses of aquatic plants to changing environments are examples of phenotypic plasticity with adaptive value (Minorsky 2003; Sculthorpe 1967; Wanke 2011; Wells and Pigliucci 2000).

Aquatic plants are thought to have evolved from terrestrial ancestors, and to have adapted secondarily to aquatic habitats. They include both heterophyllous and obligate submerged homophyllous (non-heterophyllous) species (Cook 1990, 1999). Heterophyllous species produce submerged and aerial leaves (i.e., floating and/or terrestrial). The structure of the aerial leaves is similar to that of land plants, while the submerged leaves are thin, elongated and lack differentiation of the stomata, cuticle and mesophyll layers. Many environmental factors, such as water stress, photoperiod, and temperature, affect heterophyllous leaf formation (reviewed by Kuwabara and Nagata 2002; Wells and Pigliucci 2000). 
The plant hormone abscisic acid (ABA) plays an important role in mediating the adaptation to stress (i.e., drought, salinity and cold), including rapid regulation of stomatal behaviors that control water loss through transpiration. It has been suggested that ABA is a long-distance signaling molecule that is continuously transported from mature leaves to developing leaves to optimize performance under the prevailing environmental changes (reviewed by Chater et al. 2014). In the ABA biosynthesis pathway, a key regulated step is catalyzed by 9-cis-epoxycarotenoid dioxygenase (NCED) (Zeevaart and Creelman 1988). The NCED is encoded by a multigene family, and stress-inducible members contribute a rate-limiting step of ABA biosynthesis (Finkelstein 2013). After exposure to water deficit, ABA concentration is increased 2- to 30-fold, which lead to stress responses and activation of ABA biosynthesis pathway, in particular, the expression of NCED genes is upregulated (Iuchi et al. 2001; Qin and Zeevaart 1999).

In aquatic plants, ABA content of submerged leaves is undetectable or very low (i.e., $0-6.5 \mathrm{ng} \mathrm{g}^{-1}$ fresh weight), as compared with that of terrestrial plant leaves (i.e., 20-400 $\mathrm{ng} \mathrm{g}^{-1}$ fresh weight) (Milborrow and Robinson 1973; Qin and Zeevaart 1999; Wright 1977; Zeevaart 1980). When heterophyllous plants experience osmotic stress, ABA concentrations increase and aerial leaves are generated (Goliber and Feldman 1989; Milborrow and Robinson 1973). Additionally, the application of exogenous ABA induces new leaves to grow like aerial leaves, even under submerged conditions. The effects of ABA on leaf shape and structure have been described for phylogenetically diverse heterophyllous plants, including species from the genera Potamogeton L., Callitriche L., Hippuris L., Ludwigia L., Ranunculus L., and Marsilea L. (fern) (Anderson 1978; Kuwabara and Nagata 2002; Wells and Pigliucci 2000). However, the effects of exogenous ABA have not been examined in homophyllous aquatics, which produce only submerged leaves under natural conditions.

The genus Potamogeton L. (monocotyledonous pondweeds; family: Potamogetonaceae) is the largest exclusively aquatic genus that includes heterophyllous and homophyllous species (Bradshaw 1965; Iida et al. 2004, 2009; Les and Sheridan 1990). Our recent study investigated the differences in phenotypic plasticity and natural habitats among sister Potamogeton species; heterophyllous $P$. wrightii Morong (=P. malaianus Miq.) grows in shallow freshwater and sometimes on land, while homophyllous $P$. perfoliatus L. cannot survive on land and grows exclusively in deeper fresh or brackish water (Iida et al. 2007, 2013). Because they are closely related, homophyllous species may have the morphogenetic ability to be heterophyllic. However, recent genomic analyses showed that the submerged seagrass Zostera L., which belongs to a sister family of Potamogetonaceae, has lost genes for some regulators of stomatal development, i.e., SCRM2/ICE2, SPCH, MUTE, and FAMA (Golicz et al. 2015; Olsen et al. 2016).

The purpose of this study is to identify whether differences in morphogenetic potential and/or physiological stress responses are responsible for variation in phenotypic plasticity between heterophyllous and homophyllous aquatic plants. The responses under ABA and diluted seawater treatments were compared between $P$. wrightii (heterophyllous) and its allied P. perfoliatus (homophyllous). Firstly, we addressed how exogenous ABA affects morphological traits and expression of genes involved in stomatal development and ABA biosynthesis. Secondary, we analyzed response to salinity stress that may activate NCED gene expression.

\section{Materials and methods}

\section{Plant materials and stress treatments}

Potamogeton wrightii (Potamogeton malaianus Miq. [synonym]; Japanese name: Sasabamo) and P. perfoliatus (Hirohanoebimo) samples were collected from Lake Biwa in Shiga, Japan $\left(35^{\circ} 7^{\prime} \mathrm{N}, 135^{\circ} 55^{\prime} \mathrm{E}\right)$. They were maintained and propagated vegetatively using rhizomes in experimental ponds at Kobe University. For stock plants, submerged and terrestrial shoots were cultivated following the procedures of Amano et al. (2012) and lida et al. (2007).

Submerged shoots with several rhizome segments were treated with various stresses, including ABA (SigmaAldrich, Tokyo, Japan), salinity [artificial seawater (SW): SEALIFE; Marinetech, Tokyo, Japan], polyethylene glycol (PEG) 6000 (Nacalai, Kyoto, Japan), and cold $\left(5{ }^{\circ} \mathrm{C}\right.$ water temperature). Submerged shoots were precultivated in basal medium, which consisted of $0.1 \%$ Hoagland's solution (pH 7.0) (Hoagland and Arnon 1950), at $25{ }^{\circ} \mathrm{C}$ under a 12 -h photoperiod with a light intensity of $100 \mu \mathrm{mol} \mathrm{m} \mathrm{m}^{-2} \mathrm{~s}^{-1}$. Treatments were completed in basal medium, except for salinity stress. The culture medium was changed every second day (for ABA treatments) or every week. For long-term cultivation, rhizome segments were planted in a container filled with sand or in a rock wool block (for ABA treatments). For short-term cultivation, submerged shoots were transferred to glass bottles and treated starting at 10:30 am. After treatments, several mature and young folded leaves (including apical meristems) were harvested, frozen in liquid nitrogen, and stored at $-80{ }^{\circ} \mathrm{C}$ for gene expression analyses.

\section{Gene expression analysis}

The extraction of total RNA and synthesis of cDNA were completed as previously described (Amano et al. 2012). 
Potamogeton homologs of genes involved in stomatal development; a positive regulatory peptide (STOMAGEN; Sugano et al. 2010) and basic helix-loop-helix transcription factors (i.e., ICE, SPCH, MUTE, and FAMA; Pillitteri and Torii 2012), and NCEDs were identified by de novo sequencing of RNA from developing leaves of terrestrial shoots (P. wrightii) and from mature leaves of submerged shoots treated with low temperature stress $\left(15^{\circ} \mathrm{C}\right)$ (P. wrightii and P. perfoliatus). The RNA sequencing was completed by the Takara de novo RNA-seq service (Takara Bio Inc., Kusatsu, Japan). Sequences obtained in this study were deposited in the DNA Data Bank of Japan, and the gene accession numbers are provided in Supplemental Table S1. Functional annotations were based on sequence similarity searches. Gene-specific primers for reverse transcription (RT)-PCR were designed according to the obtained sequences (Table S2).

The RT-PCR and quantitative real-time RT-PCR were conducted following standard protocols (Amano et al. 2012). The RT-PCR amplification was completed with 30 cycles (for ACTIN and NCEDI-4) or 35 cycles (for NCED5, NCED6, STOMAGEN, ICE, SPCH, MUTE, and FAMA) of $95^{\circ} \mathrm{C}$ for $30 \mathrm{~s}$ and $58-60^{\circ} \mathrm{C}$ for $30 \mathrm{~s}$ using genespecific primers (Table S2). ACTIN (Table S1) was used as a positive internal control. All experiments were repeated at least three times using independently prepared total RNA.

\section{Data analysis}

Mature expanded leaves that developed for 30 days after each treatment were used in morphological parameter measurements. Stomatal density on the leaf surfaces was calculated as described by Iida et al. (2007). Morphological differences among cultivation conditions and real-time RTPCR analysis of NCED genes were assessed by ANOVA and Tukey's multiple comparison test.

\section{Results}

\section{Effects of exogenous ABA on stomatal production}

Plants were treated with different concentrations of ABA (Fig. 1; Supplemental Fig. S1, Table S3). As early as 4 days after $10 \mu \mathrm{M}$ ABA treatment was initiated, the main shoots exhibited a species-specific response (Fig. S1). In $P$. wrightii plants, mature leaves were damaged, but new leaves with stomata continued to emerge from the main shoot. The majority of $P$. perfoliatus mature leaves remained green. Additionally, new leaves did not emerge from the main shoot, in which the stem near the top became damaged and broke off about 10 days after $10 \mu \mathrm{M}$ ABA treatment. Thereafter, both species produced new rhizome buds with adventive roots, which sprouted and formed new shoots bearing leaves with stomata (Fig. 1d, e). Following treatment with $10 \mu \mathrm{M} \mathrm{ABA}$, the culture medium was removed and plants containing leaves with stomata were exposed to the air and cultivated under moist conditions. Potamogeton wrightii plants continued to produce new leaves with stomata, but $P$. perfoliatus plants withered and died within 20-30 days. Damage to pre-existing leaves and shoots was not observed in either species following treatment with 1.0 $\mu \mathrm{M}$ ABA (Fig. S1). Additionally, new leaves with stomata were produced only in $P$. wrightii plants (Fig. 1g; Table S3).

In $P$. wrightii plants, ABA treatment $(1.0$ or $10 \mu \mathrm{M})$ resulted in the production of stomata-containing leaves that resembled terrestrial leaves, with a short petiole and oblong leaf-blade (Fig. 1b, d, f, g; Table S3). Furthermore, the effects of ABA on leaf shape and stomatal density were dose-dependent (Fig. 1f, g). Increasing ABA concentrations resulted in a decrease in the ratio of leaf blade length to width (L/W ratio) because the leaf shape changed from narrow to broad. Stomata were produced after 1.0 or $10 \mu \mathrm{M}$ ABA treatments, and stomatal density increased from $0 \pm 0$ to $70 \pm 13$ to $96 \pm 17 \mathrm{~mm}^{-2}$ with increasing ABA concentration (i.e., $0.1,1.0$, and $10 \mu \mathrm{M}$, respectively). The ABA dose response of $P$. perfoliatus plants was considerably different from that of $P$. wrightii plants (Fig. 1f, g; Table S3). Regardless of ABA concentration, leaf shape and the L/W ratio remained unchanged. Stomata were produced at a density of $17 \pm 4 \mathrm{~mm}^{-2}$ only after treatment with $10 \mu \mathrm{M}$ ABA (Fig. 1e, g).

Because continuous exposure to $\mathrm{ABA}$ is required for the stable production of underwater leaves with stomata (Goliber and Feldman 1989; Hsu et al. 2001), we examined the effects of temporary ABA treatment on stomatal formation. Plants were treated with $10 \mu \mathrm{M}$ ABA for 4 days and transferred to ABA-free basal medium (Fig. S2). In both species, leaves with stomata were only produced when exogenous ABA was present. Additionally, the morphology of newly formed leaves changed from stomata-less and submerged to stomata-containing and terrestrial-like (following ABA treatment), and then back to stomata-less and submerged (after ABA was removed).

\section{Response of regulators of stomatal development to ABA}

To confirm stomatal production in Potamogeton species, gene expression analyses were completed using young folded leaves (apical meristem included). Potamogeton homologs of genes encoding regulators of stomatal development (i.e., PotSTOMAGEN, PotICE1, PotICE2, PotSPCH, PotMUTE, and PotFAMA) were identified (Table S1; Figs. 2, S3-S5). In plants grown in freshwater conditions (without ABA), STOMAGEN and MUTE were 
Fig. 1 Effect of exogenous abscisic acid (ABA) on morphological traits in Potamogeton species. Representative heterophyllous $P$. wrightii shoot, leaf, and adaxial leaf surface from underwater (control) (a) and terrestrial (b) environments. Homophyllous $P$. perfoliatus samples from underwater (control) conditions (c). Potamogeton wrightii $(\mathbf{d})$ and P. perfoliatus (e) samples from plants cultivated in $10 \mu \mathrm{M}$ ABA solution (for 30 days at $20^{\circ} \mathrm{C}$ ). Scale bars correspond to $5 \mathrm{~cm}$ (shoot), $2 \mathrm{~cm}$ (leaf), and $20 \mu \mathrm{m}$ (leaf surface). Leaf shape determined by the leaf blade length to width ratio (L/W ratio) (f). Stomatal density on the adaxial leaf surface of plants cultivated for 30 days in $\mathrm{ABA}(0,0.1$, 1.0 , and $10 \mu \mathrm{M})(\mathbf{g})$. T: data for terrestrial leaves adapted from Iida et al. (2007). Means followed by the same letter are not significantly different $(P<0.05$; Tukey's multiple comparison test, $n=15$ ). Error bars indicate the standard deviation
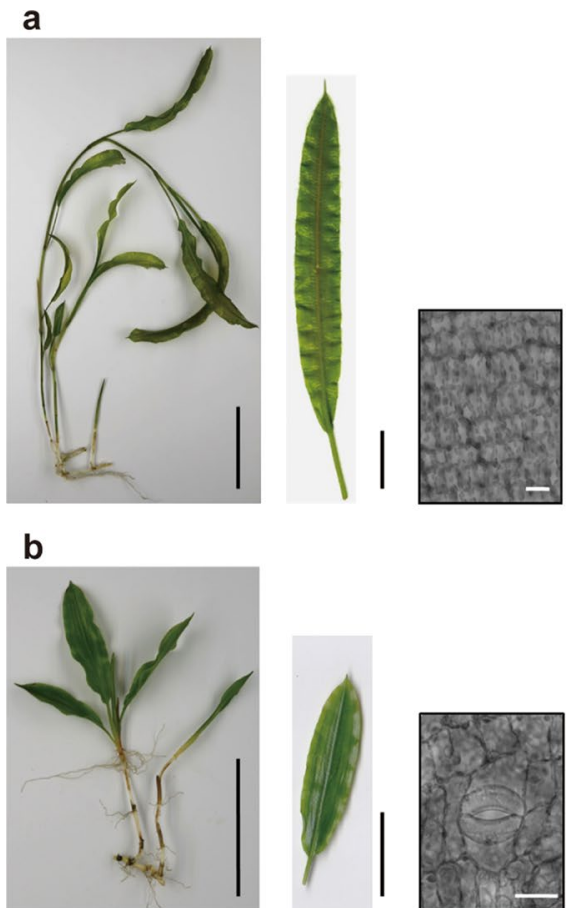

d
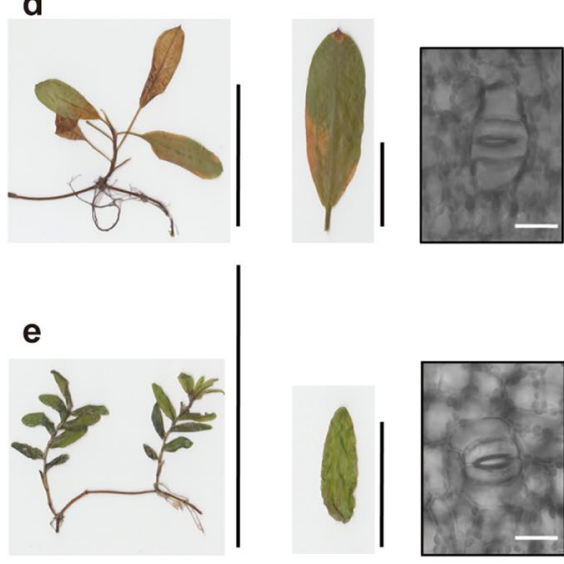

C

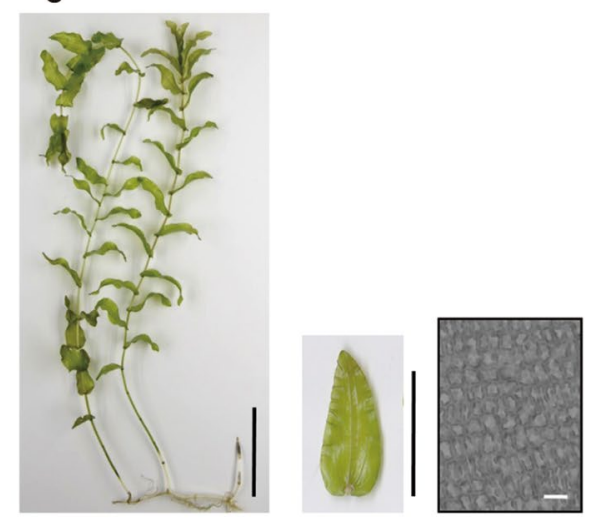

f

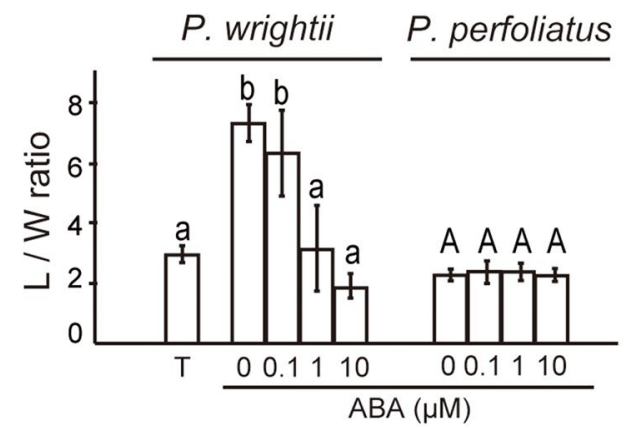

g

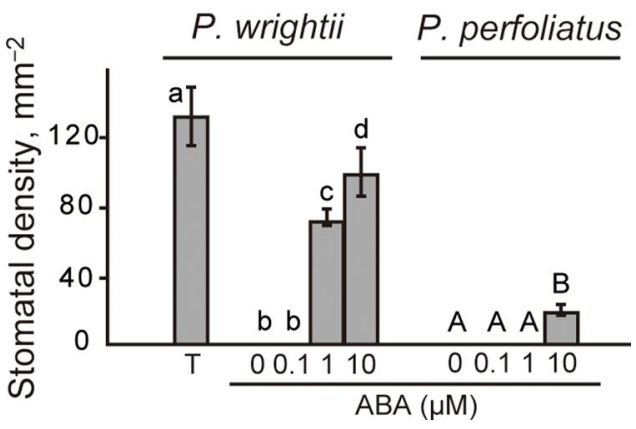

unexpressed (Fig. 2). In P. wrightii, STOMAGEN and all five transcription factor genes were expressed 2 days after ABA treatments, similar to the gene expression pattern in plants grown under terrestrial conditions (Fig. 2). The six genes were also expressed in $P$. perfoliatus treated with $10 \mu \mathrm{M} \mathrm{ABA}$, and the gene expression patterns following exposure to $1 \mu \mathrm{M}$ ABA were identical to those observed under freshwater conditions (Fig. 2).

\section{Identification of $N C E D$ genes and analyses of expression}

Six NCED-like genes were identified by de novo RNA sequencing, namely PotNCED1-6 (Table S1; Figs. 3, S6S8). Genomic PCR results revealed that the amplified fragments lacked intron sequences, which is a characteristic of
NCED genes, for all genes except NCED2 (Fig. S8; Tan et al. 2003). The sequences of NCEDI-3 were similar to that of AtNCED4 (CCD4: carotenoid cleavage dioxygenase), which is not involved in ABA biosynthesis (Figs. S6, S7; Gonzalez-Jorge et al. 2013). The NCED4-6 sequences were similar to those of other genes associated with ABA biosynthesis activity, including a sequence corresponding to a residue responsible for substrate specificity (Messing et al. 2010, Fig. S7).

Because ABA is synthesized and transported from mature to young leaves, the expression patterns of NCED genes were analyzed in mature leaves (Fig. 3). NCED1, NCED2 ( $P$. perfoliatus), and NCED4 transcripts were barely detected (Fig. 3). Under osmotic stress conditions (i.e., PEG and SW treatments), NCED2 (P. wrightii) and NCED3 transcript levels decreased, whereas those of 


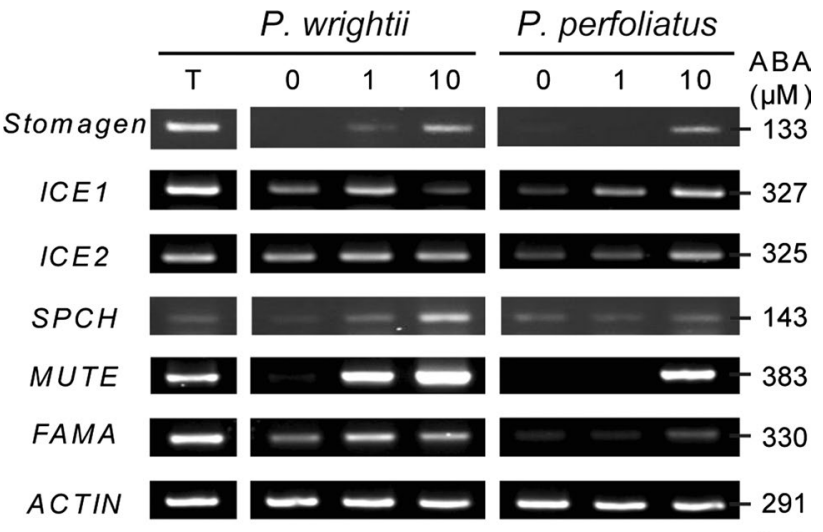

(bp)
Fig. 2 Response of regulators of stomatal development to abscisic acid (ABA) in Potamogeton species. Total RNA was extracted from young folded leaves of $P$. wrightii terrestrial shoots (T) and submerged shoots of $P$. wrightii and $P$. perfoliatus 2 days after ABA treatment $(0,1$, and $10 \mu \mathrm{M})$. Gene expression of regulators of stomatal development (i.e., STOMAGEN, ICE1, ICE2, SPCH, MUTE, and FAMA) were analyzed by reverse transcription PCR using genespecific primers (Table S2). ACTIN served as a control. The numbers correspond to the length of specific regions. Results were consistent among three independent experiments

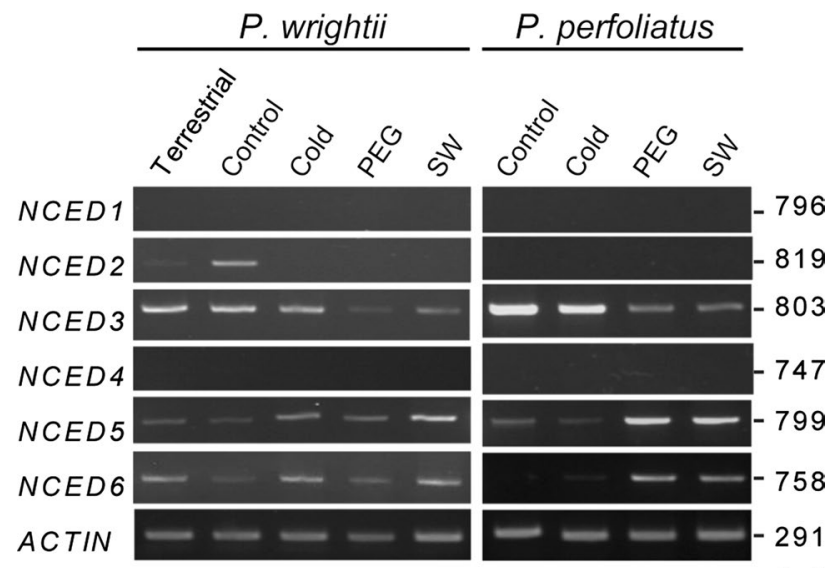

(bp)

Fig. 3 Potamogeton species NCED gene expression levels in response to stress. Total RNA was extracted from mature leaves of submerged shoots $2 \mathrm{~h}$ after each treatment (Cold: $5{ }^{\circ} \mathrm{C}$; PEG: $20 \%$ polyethylene glycol 6000 , solute potential: $\Psi \pi=-0.67 \mathrm{MPa}$; SW: $1 / 3$ strength seawater, solute potential: $\Psi \pi=-0.76 \mathrm{MPa})$. Results for leaves from non-stressed terrestrial shoots (terrestrial) and submerged shoots (control) are also provided. The other details are the same as those of Fig. 2

NCED5 and NCED6 were up-regulated in both species (Fig. 3).

The expression of NCED5 was relatively stable regardless of ABA concentration $(1$ or $10 \mu \mathrm{M})$ and treatment times ( $2 \mathrm{~h}$ or 2 days) in both species (Fig. 4). In contrast, NCED6 expression in both species was highly induced
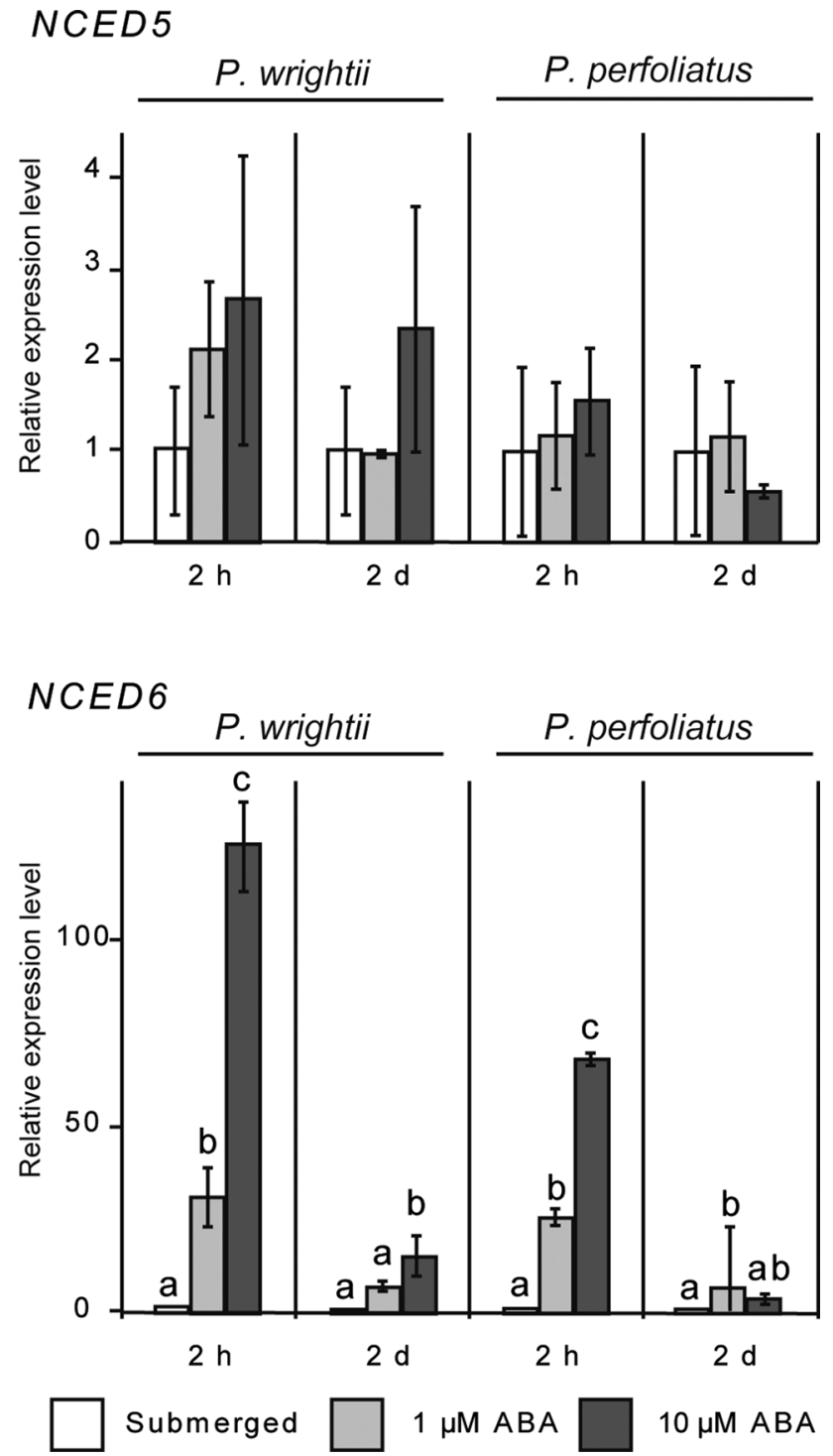

Fig. 4 Quantitative real-time PCR analyses of stress-responsive NCED genes in Potamogeton species following application of exogenous abscisic acid (ABA). Total RNA was extracted from mature expanded leaves $2 \mathrm{~h}$ or 2 days after ABA treatments $(1$ or $10 \mu \mathrm{M})$. Transcript expression levels were normalized to that of ACTIN and are provided as values relative to those of the submerged control. Data are expressed as the mean values of three individual experiments $(\mathrm{n}=3)$. Error bars indicate the standard deviation. Significant differences among treatments were detected for NCED6 in both species (ANOVA, $P<0.001$ ). Means followed by the same letter are not significantly different (Tukey's multiple-comparison test, $P<0.05$ )

$2 \mathrm{~h}$ after ABA treatment, but decreased to near control levels after 2 days (Fig. 4). Relative expression levels $2 \mathrm{~h}$ after treatments were positively correlated with exogenous ABA concentration (P. wrightii: $1 \mu \mathrm{M}$ : $30.9 \pm 7.8-$ fold and $10 \mu \mathrm{M}$ : $125.5 \pm 12.1$-fold; P. perfoliatus: $1 \mu \mathrm{M}$ : $25.4 \pm 2.1$-fold and $10 \mu \mathrm{M}: 67.9 \pm 16.5$-fold) (Fig. 4). 
Fig. 5 Cultivation of Potamogeton species exposed to salinity stress. Shoot, leaf, and adaxial leaf surface of heterophyllous $P$. wrightii $(\mathbf{a}, \mathbf{b})$ and homophyllous $P$. perfoliatus (c, d) plants. Pre-existing (a, c) and newly formed shoots (b, d) were sampled following growth in artificial seawater $(1 / 6$ strength for 1 week followed by $1 / 3$ strength for 30 days). Scale bars correspond to $5 \mathrm{~cm}$ (shoot), $2 \mathrm{~cm}$ (leaf), and $20 \mu \mathrm{m}$ (leaf surface). Leaf shape (L/W ratio) (e) and stomatal density (f) on the adaxial surface of leaves on newly formed shoots. The other details are the same as those of Fig. 1

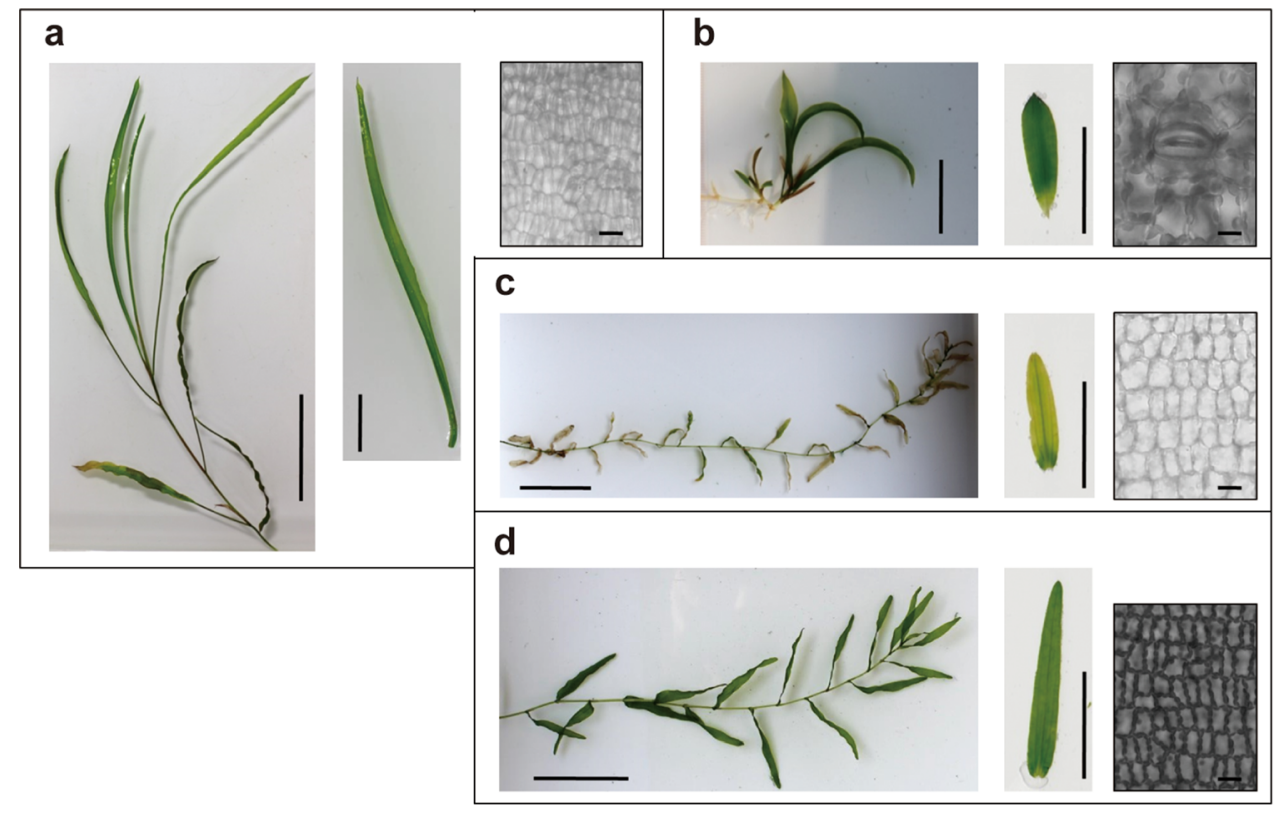

e

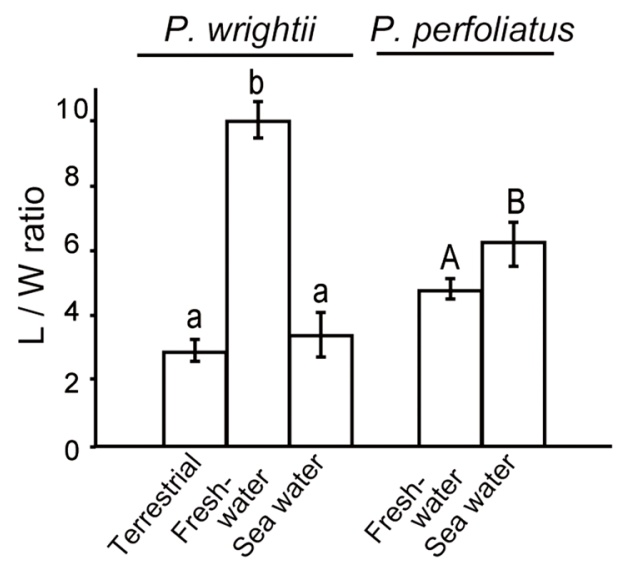

f

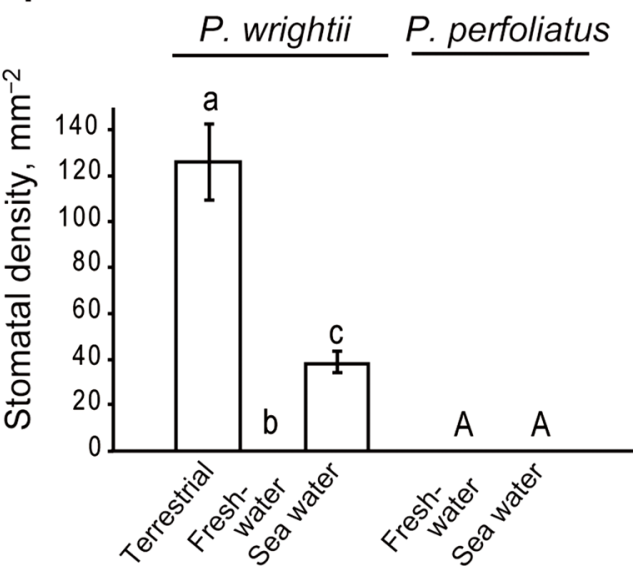

\section{Comparison of the effects of salinity stress}

Plants were initially cultivated in different concentrations of artificial SW (in $500 \mathrm{~mL}$ glass bottles). Under $1 / 6$ strength SW (hereafter 1/6 SW), both species exhibited no obvious growth changes. This salinity level is much higher than that of the natural habitats of these species [i.e., maximum of $1 / 33 \mathrm{SW}$ for $P$. wrightii and $1 / 16 \mathrm{SW}$ for $P$. perfoliatus, based on $\mathrm{Cl}^{-}$concentrations (Kadono 1982)]. The $P$. wrightii leaves were damaged, but not those of $P$. perfoliatus, following treatment with $1 / 3 \mathrm{SW}$ for 1 week (with no pre-treatment).

Potamogeton wrightii plants pre-treated with $1 / 6 \mathrm{SW}$ for 1-2 weeks exhibited no leaf damage following treatment with 1/3 SW (Fig. 5). Dwarf shoots with short internode stems emerged from the rhizome 2 weeks after $1 / 3 \mathrm{SW}$ culture (Fig. 5b). The leaves on the dwarf shoots had short petioles, were smaller and rounder than normal submerged leaves, and bore stomata on the adaxial and abaxial sides. Additionally, stomatal density was lower than that of terrestrial leaves (Fig. 5b, e, f; Table S4). Salinity treatments caused pre-existing $P$. wrightii shoots to stop growing, and their leaf margins rolled inward (Fig. 5a). In contrast, salinity stress had no apparent effect on the growth of pre-existing or newly developed $P$. perfoliatus shoots (Fig. 5c, d). New leaves were narrow with a lack of stomata (Fig. 5c-f; Table S4). After exposure to salinity stress for 3 months, $P$. perfoliatus plants continued to produce submerged shoots, while $P$. wrightii shoots containing leaves with stomata exhibited delayed growth and eventually died. Because salinity stress involves ionic and osmotic components, plant responses to osmotic stress were examined using $20 \%$ PEG 6000. The solute potential $(\Psi \pi=-0.67 \mathrm{MPa})$ of this PEG concentration is similar to that of $1 / 3 \mathrm{SW}$ treatment $(\Psi \pi=-0.76 \mathrm{MPa}$ ). The mature leaves of $P$. wrightii were more severely damaged than those of $P$. perfoliatus 
Fig. 6 Temporal stress-responsive $N C E D$ gene expression in Potamogeton species. Submerged shoots were pre-treated with $1 / 6$ strength seawater $(1 / 6$ $\mathrm{SW})$ for 1 week and transferred to $1 / 3$ strength seawater $(1 / 3$ SW). Total RNA was extracted from mature expanded leaves at specific time points $(1 / 6 \mathrm{SW}$ : $0 \mathrm{~h}, 2 \mathrm{~h}, 1$ day, and 7 days; $1 / 3$ SW: 2 h, 1 day, and 7 days). Significant differences among treatments were detected for NCED5 and NCED6 in both species (ANOVA, $P<0.001$ ). The other details are the same as those of Fig. 4

\section{NCED 5}
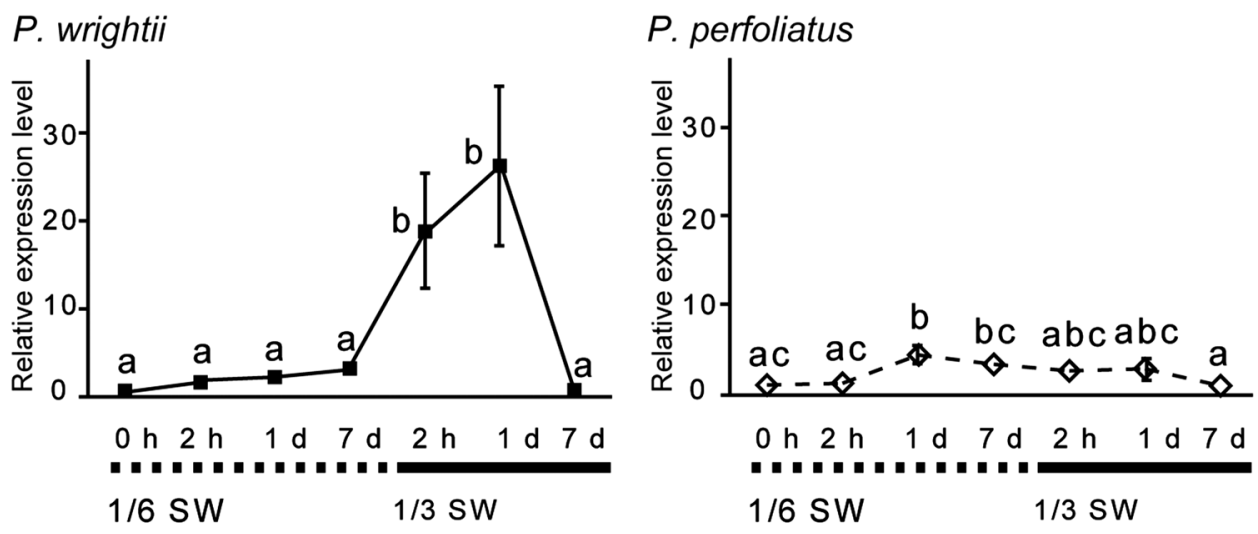

\section{NCED 6}

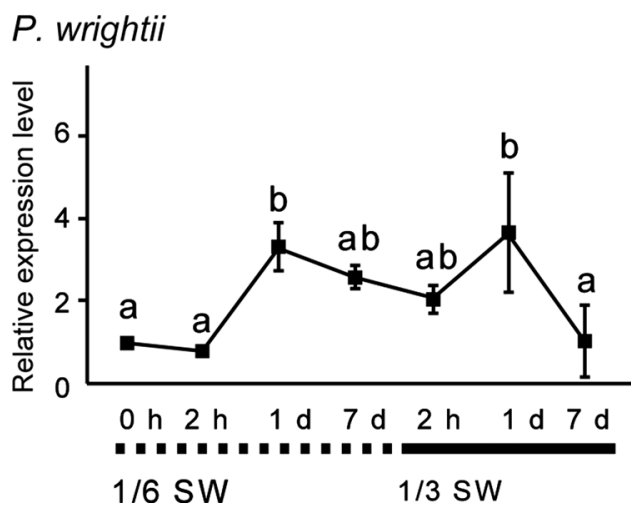

(Fig. S9). The PEG treatment induced the production of leaves with stomata at an average density of $47 \pm 9 \mathrm{~mm}^{-2}$ (adaxial side, $\mathrm{n}=5$ ) in $P$. wrightii plants only (Fig. S9).

The expression of stress-responsive NCED genes was examined in mature leaves from the main shoot during the $1 / 6 \mathrm{SW}$ pre-treatment period and from plants treated with 1/3 SW for 7 days (Fig. 6). In P. wrightii, NCED5 expression increased considerably 1 day after treatment with $1 / 3$ SW (26.2 \pm 9.1 -fold), whereas the NCED 5 transcript level was consistently low (0.8-4.4-fold) in $P$. perfoliatus (Fig. 6). The expression of NCED 6 was up-regulated in $P$. wrightii 1 day after $1 / 6$ and $1 / 3 \mathrm{SW}$ treatments $(3.4 \pm 0.6$ fold and $3.7 \pm 1.4$-fold, respectively). In contrast, the up-regulation of NCED6 in P. perfoliatus was not significant following treatment with $1 / 3 \mathrm{SW}$, but its expression increased 1 day after exposure to $1 / 6 \mathrm{SW}(6.5 \pm 0.9$-fold $)$ (Fig. 6).

\section{Discussion}

In this study, exogenous ABA application induced stomatal leaves in obligate submerged species $P$. perfoliatus as well as in heterophyllous $P$. wrightii (Fig. 1). However, under salinity stress, which often promotes ABA biosynthesis, stomata were induced in $P$. wrightii, but not in $P$. perfoliatus (Fig. 5). These results suggested that, between the two Potamogeton plants, differences in the ABA-mediated stress responses, but not in the morphogenetic potential, were responsible for variation in phenotypic plasticity under natural conditions.

\section{ABA-mediated production of stomata in Potamogeton species}

The induction of stomatal leaves by applying ABA was first reported in heterophyllous Potamogeton nodosus (Anderson 1978), and has since been demonstrated in a wide range of heterophyllous aquatics (Minorsky 2003). It has been shown that treatment with exogenous ABA $(1.0-10 \mu \mathrm{M})$ effectively induces stomatal development, even in freshwater (Anderson 1978, 1982; Deschamp and Cooke 1983, 1984; Goliber and Feldman 1989; Kane and Albert 1987; Kuwabara et al. 2003; Liu 1984). To consistently produce leaves with stomata underwater, plants must be continuously exposed to a source of exogenous ABA (Goliber and Feldman 1989; Hsu et al. 2001). Even in homophyllous plants, the results of our exogenous ABA experiments are 
consistent with those of previous studies (Figs. 1, S1, S2). In heterophyllous $P$. wrightii and its allied homophyllous $P$. perfoliatus, the continuous application of ABA led to the production of stomata on underwater leaves.

Although the expression patterns of regulatory genes for stomatal development were almost identical, the response to exogenous ABA differed between the two examined species (Figs. 1, 2; Table S3). In P. wrightii, stomata were produced by $1.0 \mu \mathrm{M}$ of $\mathrm{ABA}$ treatment and the effect of exogenous $\mathrm{ABA}$ on leaf shape and stomatal density was dosage-dependent, but not in P. perfoliatus (Fig. 1; Table S3). These results indicate that $P$. perfoliatus was less sensitive to exogenous ABA. There are two possible explanations for the species-specific differences. The first is differences in positive feedback regulation of ABA. After exposure to osmotic stress, many ABA biosynthesis genes, including $N C E D s$, are up-regulated by a positive feedback mechanism, which results in the accumulation of ABA (Welsch et al. 2008; Xiong and Zhu 2003). It was found that exogenous ABA stimuli increases the expression of NCED genes in rice and certain ecotypes of Arabidopsis, but not in tomato and cowpea plants (Iuchi et al. 2000; Thompson et al. 2000; Welsch et al. 2008; Xiong et al. 2002). In Potamogeton, NCED5 and NCED6 were expected to be involved in ABA synthesis under abiotic stress conditions (Figs. 3, 4, 6, S6-S8). We suspect that positive feedback regulation through exogenous ABA operated insufficiently in P. perfoliatus. However, it was unclear whether there was a positive feedback effect on the transcription of NCED5 in both examined species. Although the relative NCED6 expression levels $2 \mathrm{~h}$ after treatments were positively correlated with exogenous ABA concentrations, the up-regulation of expression was transient (Fig. 4). The second explanation is that $P$. perfoliatus is more tolerant to ABA and thus less likely to respond to ABA. This is a more plausible explanation, because following treatment with $10 \mu \mathrm{M}$ ABA, P. wrightii leaves were severely damaged, while $P$. perfoliatus leaves were relatively unaffected (Fig. S1). Additionally, the relative NCED6 expression level was more increased in $P$. wrightii than that in P. perfoliatus (Fig. 4).

Previous studies of aquatic plants reported that $A B A$ acts as an on/off switch for stomata (aerial leaf) formation depending on whether ABA is above the threshold for concentration and treatment time (Lin 2002; Wanke 2011). Although we did not measure ABA content, the consistent up-regulation of NCED expression in P. wrightii under salinity stress conditions may have resulted in the continuous accumulation of ABA, leading to the production of stomata on underwater leaves (Figs. 5, 6). In contrast, the induction of $P$. perfoliatus NCED expression was temporary, resulting in a lack of stomata (Figs. 5, 6). We conclude that heterophyllous $P$. wrightii and homophyllous $P$. perfoliatus have an innate morphogenetic ability to form stomata, but the actual production of stomata depends on ABA-mediated stress responses specific to each species.

\section{Responses to environmental stresses and habitat specificity of Potamogeton species}

Abscisic acid is synthesized de novo during exposure to osmotic stress conditions (i.e., drought, salinity, and cold), and plays important roles in stress tolerance. Submerged $P$. wrightii shoots were sensitive to salinity stress, and developed ABA-mediated morphological plasticity (Fig. 5; Table S4). Terrestrial shoots were produced in seawater, but the submerged leaves with stomata were unsuitable for photosynthesis. As revealed in other aquatic plants (Goliber and Feldman 1989), the plasticity was related to osmotic stress responses because the $P$. wrightii leaves with stomata were also formed following PEG treatment (Fig. S9). Previous studies have reported that $P$. wrightii is drought and heat tolerant and able to survive on land by producing terrestrial shoots (Amano et al. 2012; Iida et al. 2007). Similar to ABA and salinity stresses, osmotic stress during exposure to drought conditions induces phenotypic changes that enable $P$. wrightii to survive on land along the shores of freshwater bodies.

In contrast, $P$. perfoliatus is sensitive to drought and heat stress and unable to survive on land (Amano et al. 2012; Iida et al. 2007). However, it can spread in both fresh and brackish waters. Although the two Potamogeton species examined in this study inhabit the freshwater conditions of Lake Biwa, P. perfoliatus exhibited normal growth with undamaged leaves following $1 / 3 \mathrm{SW}$ treatment. The submerged $P$. perfoliatus shoots may have an innate tolerance to salt and osmotic stress. Most plants respond to salinityinduced osmotic stress immediately after salt concentrations exceed a threshold value (approximately $40 \mathrm{mM}$ $\mathrm{NaCl}$; Munns and Tester 2008). Salt tolerant plants synthesize less ABA than sensitive plants, and can grow normally under medium salinity stress conditions (He and Cramer 1996; Kefu et al. 1991). The seedlings of the AtNCED3deficient $A$. thaliana mutant, which is unable to accumulate ABA upon exposure to stress, grows more rapidly than wild-type seedlings following treatment with $160 \mathrm{mM}$ $\mathrm{NaCl}$ (roughly corresponding to $1 / 3 \mathrm{SW}$ ) (Ruggiero et al. 2004). NCED6 was up-regulated transiently (Fig. 6), suggesting that $P$. perfoliatus could rapidly acclimate to saline conditions, with no apparent growth effects or morphological plasticity. The suppression of stomatal development and preservation of submerged traits in salt tolerant $P$. perfoliatus plants is favorable for underwater life in fresh to brackish water, but not for life on land.

Terrestrial plants evolved from aquatic algae through the development of increasingly complex structures and 
functions. Gaining the ability to produce stomata following exposure to abiotic stresses was a key evolutionary step that enabled plants to grow in terrestrial environments. Homophyllous aquatic plants, which permanently returned to underwater life, do not produce leaf stomata, and water and gas can pass directly across the leaf epidermis. Transitional states between exclusively aquatic or terrestrial lifestyles have been observed in heterophyllous aquatic plants that ordinarily grow submerged in water, but produce terrestrial shoots on land during seasonal drought conditions. Our findings suggest that by modifying responses to osmotic stress conditions, homophyllous plants can grow even in saline water. Such evolutionary changes may have generated ecological diversity that extended plant habitats from land to freshwater and even to marine environments.

Acknowledgments This work was supported by the Japan Society for the Promotion of Science Grant-in-Aid for Scientific Research (JSPS-KAKENHI; Grant Numbers 25440209, 25840156, and 15K07221).

\section{Compliance with ethical standards}

Conflict of interest The authors declare that they have no conflict of interest.

\section{References}

Amano M, Iida S, Kosuge K (2012) Comparative studies of thermotolerance: different modes of heat acclimation between tolerant and intolerant aquatic plants of the genus Potamogeton. Ann Bot 109:443-452. doi:10.1093/aob/mcr300

Anderson LWJ (1978) Abscisic acid induces formation of floating leaves in the heterophyllous aquatic angiosperm Potamogeton nodosus. Science 201:1135-1138. doi:10.1126/ science.201.4361.1135

Anderson LWJ (1982) Effects of abscisic acid on growth and leaf development in American pondweed (Potamogeton nodosus Poir.) Aquat Bot 13:29-44. doi:10.1016/0304-3770(82)90038-9

Bradshaw AD (1965) Evolutionary significance of phenotypic plasticity in plants. Adv Genet 13:115-155

Chater CCC, Oliver J, Casson S, Gray JE (2014) Putting the brakes on: abscisic acid as a central environmental regulator of stomatal development. New Phytol 202:376-391. doi:10.1111/nph.12713

Cook CDK (1990) Aquatic plant book. SPB Academic Publishing, Hague

Cook CDK (1999) The number and kinds of embryo-bearing plants which have become aquatic: a survey. Perspect Plant Ecol Evol Syst 2:79-102. doi:10.1078/1433-8319-00066

Deschamp PA, Cooke TJ (1983) Leaf dimorphism in aquatic angiosperms: significance of turgor pressure and cell expansion. Science 219:505-507. doi:10.1126/science.219.4584.505

Deschamp PA, Cooke TJ (1984) Causal mechanisms of leaf dimorphism in the aquatic Callitriche heterophylla. Am J Bot 71:319-329

Finkelstein R (2013) Abscisic acid synthesis and response. Arabidopsis Book 11:e0166. doi:10.1199/tab.0166

Goliber TE, Feldman LJ (1989) Osmotic stress, endogenous abscisic acid, and the control of leaf morphology in Hippuris vulgaris L. Plant Cell Environ 12:163-171. doi:10.1111/j.1365-3040.1989. tb01929.x
Golicz AA, Schliep M, Lee HT, Larkum AWD, Dolferus R, Batley J, Chan C-KK, Sablok G, Ralph PJ, Edwards D (2015) Genomewide survey of the seagrass Zostera muelleri suggests modification of the ethylene signalling network. J Exp Bot 66:14891498. doi:10.1093/jxb/eru510

Gonzalez-Jorge S, Ha S-H, Magallanes-Lundback M, Gilliland LU, Zhou A, Lipka AE, Nguyen Y-N, Angelovici R, Lin H, Cepela J, Little H, Buell CR, Gore MA, DellaPenna D (2013) Carotenoid cleavage dioxygenase 4 is a negative regulator of $\beta$-carotene content in Arabidopsis seeds. Plant Cell 25:4812-4826. doi:10.1105/ tpc.113.119677

He T, Cramer GR (1996) Abscisic acid concentrations are correlated with leaf area reduction in two salt-stressed rapid-cycling Brassica species. Plant Soil 179:25-33. doi:10.1007/BF00011639

Hoagland CR, Arnon DI (1950) The water-culture method of growing plants without soil. Calif Agr Exp Sta Circ 347:1-32

Hsu TC, Liu HC, Wang JS, Chen RW, Wang YC, Lin BL (2001) Early genes responsive to abscisic acid during heterophyllous induction in Marsilea quadrifolia. Plant Mol Biol 47:703-715. doi:10. 1023/A:1013612331583

Iida S, Kosuge K, Kadono Y (2004) Molecular phylogeny of Japanese Potamogeton species in light of noncoding chloroplast sequences. Aquat Bot 80:115-127. doi:10.1016/j. aquabot.2004.08.005

Iida S, Yamada A, Amano M, Ishii J, Kadono Y, Kosuge K (2007) Inherited maternal effects on the drought tolerance of a natural hybrid aquatic plant, Potamogeton anguillanus. J Plant Res 120:473-481. doi:10.1007/s10265-007-0087-y

Iida S, Miyagi A, Aoki S, Ito M, Kadono Y, Kosuge K (2009) Molecular adaptation of $r b c L$ in the heterophyllous aquatic plant Potamogeton. PLoS One 4:e4633. doi:10.1371/journal.pone.0004633

Iida S, Kadono Y, Kosuge K (2013) Maternal effects and ecological divergence in aquatic plants: a case study in natural reciprocal hybrids between Potamogeton perfoliatus and P. wrightii. Plant Species Biol 28:3-11. doi:10.1111/1442-1984.12006

Iuchi S, Kobayashi M, Yamaguchi-Shinozaki K, Shinozaki K (2000) A stress-inducible gene for 9-cis-epoxycarotenoid dioxygenase involved in abscisic acid biosynthesis under water stress in drought-tolerant cowpea. Plant Physiol 123:553-562. doi:10.1104/pp.123.2.553

Iuchi S, Kobayashi M, Taji T, Naramoto M, Seki M, Kato T, Tabata S, Kakubari Y, Yamaguchi-Shinozaki K, Shinozaki K (2001) Regulation of drought tolerance by gene manipulation of 9-cis-epoxycarotenoid dioxygenase, a key enzyme in abscisic acid biosynthesis in Arabidopsis. Plant J 27:325-333. doi:10.1046/j.1365-313x.2001.01096.x

Kadono Y (1982) Distribution and habitat of Japanese Potamogeton. Bot Mag Tokyo 95:63-76

Kane ME, Albert LS (1987) Abscisic acid induces aerial leaf morphology and vasculature in submerged Hippuris vulgaris L. Aquat Bot 28:81-88. doi:10.1016/0304-3770(87)90057-X

Kefu Z, Munns R, King RW (1991) Abscisic acid levels in NaCltreated barley cotton and saltbush. Aust J Plant Physiol 18:1724. doi:10.1071/PP9910017

Kuwabara A, Nagata T (2002) Views on developmental plasticity of plants through heterophylly. Recent Res Dev Plant Physiol 3:45-59

Kuwabara A, Ikegami K, Koshiba T, Nagata T (2003) Effects of ethylene and abscisic acid upon heterophylly in Ludwigia arcuata (Onagraceae). Planta 217:880-887. doi:10.1007/ s00425-003-1062-Z

Les DH, Sheridan DJ (1990) Biochemical heterophylly and flavonoid evolution in north American Potamogeton (Potamogetonaceae). Amer J Bot 77:453-465

Lin BL (2002) Essay 23.1. Heterophylly in aquatic plants. Plant Physiology Online Sinauer Associates http://6e.plantphys.net/ essay24.01.html. Accessed 20 Jan 2016 
Liu LBL (1984) Abscisic acid induces land form characteristics in Marsilea quadrifolia $\mathrm{L}$. Amer J Bot 71:638-644

Messing SAJ, Gabelli SB, Echeverria I, Vogel JT, Guan JC, Tan BC, Klee HJ, McCarty DR, Amzel LM (2010) Structural insights into maize viviparous 14, a key enzyme in the biosynthesis of the phytohormone abscisic acid. Plant Cell 22:2970-2980. doi:10.1105/ tpc. 110.074815

Milborrow BV, Robinson DR (1973) Factors affecting the biosynthesis of abscisic acid. J Exp Bot 24:537-548. doi:10.1093/ $\mathrm{jxb} / 24.3 .537$

Minorsky PV (2003) Heterophylly in aquatic plants. Plant Physiol 133:1671-1672. doi:10.1104/pp.900096

Munns R, Tester M (2008) Mechanisms of salinity tolerance. Annu Rev Plant Biol 59:651-681. doi:10.1146/annurev. arplant.59.032607.092911

Olsen JL, Rouzé P, Verhelst B et al (2016) The genome of the seagrass Zostera marina reveals angiosperm adaptation to the sea. Nature 530:331-335. doi:10.1038/nature16548

Pillitteri LJ, Torii KU (2012) Mechanisms of stomatal development. Ann Rev Plant Biol 63:591-614. doi:10.1146/ annurev-arplant-042811-105451

Qin X, Zeevaart JAD (1999) The 9-cis-epoxycarotenoid cleavage reaction is the key regulatory step of abscisic acid biosynthesis in water-stressed bean. Proc Natl Acad Sci USA 96:15354-15361. doi:10.1073/pnas.96.26.15354

Ruggiero B, Koiwa H, Manabe Y, Quist TM, Inan G, Saccardo F, Joly RJ, Hasegawa PM, Bressan RA, Maggio A (2004) Uncoupling the effects of abscisic acid on plant growth and water relations. Analysis of sto1/nced3, an abscisic acid-deficient but salt stresstolerant mutant in Arabidopsis. Plant Physiol 136:3134-3147. doi:10.1104/pp.104.046169

Sculthorpe CD (1967) The biology of aquatic vascular plants. Edward Arnold, London

Sugano SS, Shimada T, Imai Y, Okawa K, Tamai A, Mori M, HaraNishimura I (2010) Stomagen positively regulates stomatal density in Arabidopsis. Nature 463:241-244. doi:10.1038/ nature 08682
Tan BC, Joseph LM, Deng WT, Liu L, Li QB, Cline K, McCarty DR (2003) Molecular characterization of the Arabidopsis 9-cis epoxycarotenoid dioxygenase gene family. Plant J 35:44-56. doi:10.1046/j.1365-313X.2003.01786.x

Thompson AJ, Jackson AC, Parker RA, Morpeth DR, Burbidge A, Taylor IB (2000) Abscisic acid biosynthesis in tomato: regulation of zeaxanthin epoxidase and 9-cis-epoxycarotenoid dioxygenase mRNAs by light/dark cycles, water stress and abscisic acid. Plant Mol Biol 42:833-845. doi:10.1023/A:1006448428401

Wanke D (2011) The ABA-mediated switch between submersed and emersed life-styles in aquatic macrophytes. J Plant Res 124:467475. doi:10.1007/s10265-011-0434-x

Wells C, Pigliucci M (2000) Adaptive phenotypic plasticity: the case of heterophylly in aquatic plants. Perspect Plant Ecol Evol Syst 3:1-18. doi:10.1078/1433-8319-00001

Welsch R, Wüst F, Bär C, Al-Babili S, Beyer P (2008) A third phytoene synthase is devoted to abiotic stress-induced abscisic acid formation in rice and defines functional diversification of phytoene synthase genes. Plant Physiol 147:367-380. doi:10.1104/ pp.108.117028

Wright STC (1977) The relationship between leaf water potential ( $\Psi$ leaf) and the levels of abscisic acid and ethylene in excised wheat leaves. Planta 134:183-189. doi:10.1007/BF00384969

Xiong L, Zhu JK (2003) Regulation of abscisic acid biosynthesis. Plant Physiol 133:29-36. doi:10.1104/pp.103.025395

Xiong L, Lee H, Ishitani M, Zhu JK (2002) Regulation of osmotic stress-responsive gene expression by the LOS6/ABA1 locus in Arabidopsis. J Biol Chem 277:8588-8596. doi:10.1074/jbc. M109275200

Zeevaart JAD (1980) Changes in the levels of abscisic acid and its metabolites in excised leaf blades of Xanthium strumarium during and after water stress. Plant Physiol 66:672-678

Zeevaart JAD, Creelman RA (1988) Metabolism and physiology of abscisic acid. Annu Rev Plant Physiol Plant Mol Biol 39:439_ 473. doi:10.1146/annurev.pp.39.060188.002255 